\title{
¿QUÉ COMPRENDEMOS POR EL TÉRMINO “TI”-ALGO-, QUE EMPLEAN LOS ESTOICOS?
}

Carlos FERNANDO ANDRADA

Resumen: Intentaremos relacionar la noción estoica de "ti" -algo-, como un intento de legitimación lingüística de términos, aún cuando pueden parecer contradictorios con los rasgos esenciales de su discurso físico-cosmológico.

Carlos Fernando Andrada, “¿Qué comprendemos por el término "ti” -algo-, que emplean los estoicos?”, Claridades 5 (2013), pp 4-13.

C L A R I D A DES. REVISTA DE FILOSOFÍA

I S S N : $1889-6855$ / e I S N : $1989-3783$ / D L: P M $1131-2009$

Edita: Asociación para la Promoción de la Filosofía y la Cultura en Málaga (FICUM) 


\section{Presentación.}

Resultante de un panorama convulsionado por la evolución de los sucesos políticos y económicos del momento, el período -denominado según convención de los historiadores-, helenístico, comienza con el suceso de la repentina muerte de Alejandro Magno, concluyendo en el año 31 de nuestra era, cuando tuvo lugar la batalla de Accio, en la cual, Antonio se alza con una victoria contundente sobre Antonio. Esta época se caracteriza por la germinación de diversas corrientes de pensamiento bien específicas en su seno; ellas son: el epicureismo, el estoicismo y el cinismo. El pensamiento estoico, de nuestro interés, discurre situándose con las influencias del platonismo y el aristotelismo, y consigue encontrar con su creación teórica, un cobijo para las inclemencias de lo que estaba sucediendo en la época. En base a sus aciertos doctrinarios: pues, los estoicos no son innovadores, por el contrario, resuenan al unísono con las otras escuelas contemporáneas: los epicúreos y los cínicos, en destacar una cierta coherencia en sus planteos teóricos que adolecían en las formulaciones de las filosofías de Platón y Aristóteles.

Los estoicos, abrigan un pensamiento alejado del lugar donde estaban sucediendo verdaderamente las manifestaciones científicas, en Alejandría. Centrando su núcleo de reflexión filosófica en Macedonia, epicentro político de aquel tiempo de convulsiones y cambios históricos. Atenas entonces había dejado de protagonizar en la historia de la humanidad el centro de irradiación filosófica, cultural. Con la irrupción del estoicismo en la vida de la polis, también nace un estilo más arraigado con el legado socrático de acudir a enseñar en las galerías no ya a un selecto grupo, sino el esfuerzo va dirigido a la mayor parte posible del público. Será por esa simpatía que se supieron ganar ingresando con sus prácticas educativas, y políticas, que cuando ocurrió la muerte de Zenón, quien fuera el fundador de la estoa, la mismísima Atenas le tributa un homenaje a resultas de reconocerle que supo conseguir la "venerabilidad" que él tanto anheló. Las anécdotas reflejan que Zenón no había sido originario de Atenas, ya que había provenido de la isla de Chipre, más precisamente en Citio, lugar donde nació en el 332. Hasta no faltan comentarios de historiadores que le adjudican a Zenón, un linaje semítico. Los estoicos fueron quienes propulsaron que su pensamiento se vinculara con la política oficial del momento. Dicho acierto de esta escuela, aun perdura hasta nuestros días. La actitud de compromiso social y político atravesó la edad media, y llegó incólume a la modernidad.

El estoicismo, como corriente de pensamiento de un momento histórico donde la crisis moldea las personalidades de los hombres, va constriñendo unos tipos prefijados de modos de actuación que sobre todo en los estoicos, ponderarán a lo largo de la historia haciendo de esa impronta; un dejo distintivo de una época. La identidad de un ciudadano comprometido con la cosa pública de una ciudad -es una referencia insoslayable que configuraba a la tradición de griegos y romanos-, cede paso a otra, que insiste en persuadirnos: en que el hogar del hombre no se 
corresponde con unos parámetros de vida en comunidad, sino en una pertenencia al mundo.

El estoicismo en la historia, lo podemos fragmentar en tres momentos, en los cuales: el antiguo y el medio son muy productivos desde un enfoque filosófico, siendo el último, el de la época imperial, correspondiendo con tendencia no desinteresada a lo que acontecía en el seno mismo del imperio. Entre los distintos pensadores de que se nutrió la estoa en su larga vida, no poseyó un pensamiento monolítico, hubo divergencias. Tales fueron las mismas que en el período medio, hubo quienes orientaron la doctrina hacia el platonismo para enriquecerla.

Para acceder al conocimiento de la filosofía del período helenístico en general, y específicamente al de la estoa particularmente, dependemos únicamente de la tradición indirecta. Diógenes Laercio es quien nos ha proporcionado nutridos catálogos de títulos, que lamentablemente no se han conservado a lo largo del tiempo. Solamente podemos disponer de un patrimonio menguado de citas, probablemente textuales de ciertos pasajes, no muy extensos, integrados en obras de autores posteriores, con la dificultad de que estos autores -como Posidonio-, precisamente no se caracterizan por la imparcialidad, sino por el contrario, juzgan la obra con desmesurada animosidad.

La corriente estoica divide a la filosofía en tres ramas, sin apartarse de lo sucedido a lo largo de la historia de las ideas con otros pensadores. Dota a esta disciplina de una tripartición, esgrimiendo un orden que es de difícil cumplimiento, si la comparamos con quienes posteriormente le dieron continuidad. En principio, empiezan por la física, le sigue la ética y luego la lógica -siguiendo con atención lo que había demarcado como distinción entre proposiciones éticas, físicas y lógicas, ya Aristóteles, otros le adjudican a la Academia, en nombre de Platón, el lugar donde se origina la propuesta. La física: se muestra en el orden del mundo, la ética: en la conducta del hombre y la lógica: en el lenguaje. ${ }^{1}$

En este contexto de crisis de en lo político y en lo económico, los estoicos, sobresalen por articular una doctrina de neto corte materialista, e influida por el sino platónico y aristotélico. Otras escuelas también son alcanzados por las influencias más bien generales como son: los epicúreos y los cínicos. La estoa, va elaborando un ámbito de reflexión que escasea en originalidad, no obstante, su prevalencia en lo relativo a mantener cierta coherencia. Dada esta situación histórica, el sujeto se encuentra en soledad y empieza a barruntar que su mundo ya no lo constituye en una polis, sino que su sitio ahora es el mundo, en un horizonte abierto y sin límites, conformando así su nuevo hogar. A consecuencia de un cosmos que es regido por un logos material o dios, en el cual el sujeto se dispone a actuar con un destino prefijado, sin alteraciones, ni sorpresas.

${ }^{1}$ Juliá, V. y otros, Las exposiciones antiguas de ética estoica, Eudeba, Buenos Aires, p. 15. 
Es inherente a la corriente estoica el pregonar que su sistema pudiese difundirse para conocimiento de la mayor cantidad de sujetos posibles, de este hábito didáctico, la estoa lo recibe enfervorizadamente de los cínicos, que juntos compartieron las mismas vicisitudes de la ciudad.

\section{Aspectos de la física.}

Principian su doctrina, esgrimiendo como base de su teoría del conocimiento la aprehensión por parte de los sentidos, de la materia. Acaso le adjudican a la materia una capacidad solamente pasiva, abriendo una posibilidad de reflexión en torno a la negación taxativa del principio físico de impenetrabilidad de los cuerpos, esto es, "cuando dos cuerpos no pueden ocupar al mismo tiempo un mismo espacio". ${ }^{2}$ Llevan como insignia de su pensamiento: la mezcla y la fusión de unas materias y de unos cuerpos con otros. Admitiendo, eso sí, la omnipresencia del "logos" presidiendo a modo de "irradiación" o de una "permeable sustancia que cohesiona el todo y las partes .materiales". En el cosmos, pensado como el "órgano superior viviente", "todo se halla en contacto, y los vivientes actúan los unos sobre los otros", ya que existe una "simpatía cósmica" y una mixtura total, de manera que la totalidad de "los seres colaboran en la marcha del mundo como ser vivo"."

Es esta una presentación sistemática de la filosofía, expuesta en partes o mejor dicho, distribuidas -o bien la filosofía misma-: es el desenvolvimiento, el desarrollo de la naturaleza, para hacer manifiesto el orden del mundo, en la conducta del hombre virtuoso y en el lenguaje. Es posible que la disposición en tres partes, inaugurada entre las escuelas post-aristotélicas, han tendido a "organizar retrospectivamente el tratamiento de la producción filosófica más antigua."

La naturaleza que mantiene en conjunto al universo y que hace crecer las cosas en la tierra, es el principio creador de todo lo existente, manteniéndolo en una cohesión unitaria y vivificadora, que dirige a través de un proceso de causas y efectos con una finalidad inmanente aunque con un sentido donde prevalece lo útil y el placer de lo creado. ${ }^{4}$ La naturaleza es penetrada por el "logos", convirtiendo a este materialismo de los cuerpos en un monismo más cercano a un panteísmo vitalista que a un materialismo propiamente dicho. Encontramos en esta compleja elaboración doctrinaria, unas reminiscencias de algunos modos del pensar presocrático: pudiendo abonar con algunas citas de Heráclito, lo apuntado: "Tras haber oído al Logos y no a mí es sabio convenir en que todas las cosas son una". ${ }^{5}$

${ }^{2}$ García Gual, C. y otros, 1986, La filosofía helenistica. Éticas y sistemas, Cincel, Madrid, p. 136.

${ }^{3}$ Ibid., p. 136.

${ }^{4}$ Ibid., C. 1986, p. 134.

${ }^{5}$ Kirk, G., Raven, J. y otros, Los filósofos presocráticos, Gredos, Madrid, Heráclito: Fr. 50, p. 273. 
El estudio estoico, organizado en partes -triada-: la física, la ética y la lógica, conllevando ése orden. Siendo un sistema hermético, cerrado, cuya física tiene consecuencias en la ética, p. e. en la actuación del sujeto: aceptando el destino que ha trazado la naturaleza, no habiendo resquicio para la libertad como, en efecto, la tenían los epicúreos: situados en el limbo del jardín: alejados de todo compromiso público y por ende, político.

En la relación entre el "pneuma" y la materia que vivifica, producen las distinciones cualitativas. Es un hálito calido y estructurante de los seres. ${ }^{6}$. El cosmos que nos enseñan los antiguos estoicos, abarca todo el universo, siendo por ello, indestructible, por el contrario, a los sujetos les cabe la finitud de la existencia, no habiendo otra posibilidad de vida después de esta. Pues a ellos les pertenece el destino de la muerte. Pese a que siendo que están más cercanos al "logos divino" que los demás seres animados e inanimados.

En este cosmos, están insertos elementos materiales corporizados por el fuego que junto al aire, conforman las materias concretas y activas del sistema. Estas materias concretas son producto de las transmutaciones del fuego o soplo fogoso que al cabo de dilatados procesos terminan resolviéndose por último en prolongados y reiterados ciclos cósmicos. Tanto el fuego como el aire representan a lo más liviano y los otros dos elementos: el agua y la tierra que se afirman como pasivos en el sistema, constituyen lo más pesado. Estos cuatro elementos, en procesos cíclicos de rarefacción y condensación -que nos dejan reminiscencias de postulaciones ancestrales, procedentes de algunos filósofos presocráticos,- hacen posible la existencia de la materia individual "Ese "pneuma" que permea con su carácter vivificador toda la materia, ese principio divino de la physis, es la fuente de la actividad universal, de la eterna energía cósmica. Este "pneuma" es inteligente y dinámico. A la materia, que es indeterminada, le impone la forma y disposición particulares".?

Escuchemos a Estobeo: "Sobre los elementos que provienen de la sustancia (ousia) manifiesta (Crisipo) siguiendo a Zenón, el conductor de la escuela, algunas cosas tales como que hay cuatro elementos, fuego, aire, agua, tierra, a partir de las cuales se constituyen todas las cosas - es decir animales, plantas y el mundo todo y las cosas en él contenidas- y en los cuales todas se disuelven. También dice que el fuego es elemento por excelencia, porque a partir de él, que es el primero, se constituyen por un cambio las demás cosas y en él también se disuelven, derramándose como en el último elemento; él, en cambio, no admite el derramamiento o la disolución en otro (elemento). De acuerdo con esta exposición, se habla del fuego como de un elemento independiente, pues no se da junto con otro. Pero, de acuerdo con la primera exposición, también es

\footnotetext{
${ }^{6}$ La filosofía belenistica op. cit., pp. 138-139.

${ }^{7}$ Ibid., p. 138.
} 
constitutivo junto con los otros (elementos) porque en primer lugar se produce la transformación del fuego, por condensación, en aire; en segundo lugar, (el cambio) de éste en agua; y, en tercer lugar, según un proceso análogo, condensándose todavía más el agua, (el cambio) en tierra. Y de nuevo a partir de ésta, por disolución y derrame se produce primero la versión (chysis) en agua; en segundo término, de agua en aire; en tercer y último término, de aire en fuego. Y llama también fuego a lo que es todo ígneo, aire a lo que es aéreo y de manera similar a las restantes cosas. Según Crisipo hay tres acepciones de "elemento" en un sentido, se dice del fuego en tanto a partir de él se constituyen por transformación los demás y en él tienen su disolución; en un segundo sentido, se dice "elemento" en tanto se habla de cuatro elementos: fuego, aire, agua y tierra (pues por alguno o algunos de ellos o por todos se han constituido las demás cosas: por obra de los cuatro, cosas como la luna, qué está constituida de fuego y aire; por obra de uno solo, el sol, que consta de fuego solo pues el sol es fuego sin contaminación); en tercer sentido se llama elemento también a lo que primariamente está constituido de tal manera que proporciona generación a partir de si mismo, de una manera metódica, hasta (alcanzar) un fin (telos) y, a partir de él, recibe en sí mismo la disolución, de la misma manera metódica. Sostuvo que estas caracterizaciones de "elementos" son adecuadas porque (elemento) es lo por sí mismo fácilmente cambiante, el principio y lógos seminal y la dynamis eterna, que tiene una naturaleza tal que se mueve a sí misma hacia abajo, en el sentido del cambio y desde el cambio hacia arriba, de manera totalmente cíclica, disolviendo todas las cosas en sí mismas y, a su vez, reconstituyéndose a partir de sí misma de manera ordenada y metódica."

Los antiguos estoicos -según convención de los historiadores-, construyen una doctrina que se basa en el conocimiento de lo material, considerando como tal a lo corporal. Cuyo materialismo se destaca históricamente como renuente a aceptar al idealismo de la filosofía platónica. Hasta llegan a objetar "la solución hilemórfica de Aristóteles, y su existencia metafísica de un Primer Motor, que mueve el universo desde más allá del mundo". Tampoco admiten la existencia de un Primer Motor que mueve al universo".?

Los estoicos descollaron al presentar un sistema sin fisuras, si lo comparamos con el que propugnaron Platón y Aristóteles. Verdaderamente, la ventaja para destacar, es la teoría de la mezcla procurando que el logos -en cierto modo intraducible en nuestra lengua, siendo posible identificarla con acepciones cercanas a proporción, razón, fórmula.- sea inmanente con la materia corporal. Quedando de este modo un logos activo por un lado, y una materia pasiva por el otro. Despejando toda suspicacia de que el logos sea equivalente a un espíritu. Nada más lejos que eso. La

\footnotetext{
8 Estobeo en Eclog. I p. 129, I W en Méthexis, Revista argentina de filosofía antigua, (1990), vol. III, traducción de Victoria Juliá y Marcelo Boeri, Fondo de cultura económica, Buenos Aires.

${ }^{9}$ La fillosofia belenística op. cit., p. 133.
} 
naturaleza, o sea dios, todo lo rige, de ahí que su concepción monista alcance la orientación ética de los sujetos. Es un cosmos que rige a todos por igual, habiendo en consecuencia, un destino, una necesidad. El sujeto, con semejante panorama, no está entregado al acaso. De ahí que el estoico se siente seguro cuando sabe que el logos, todo lo preside. Únicamente el cosmos es indestructible, a los hombres les cabe la finitud, no siendo posible la reinstauración de otra vida después de esta, salvo que ingresemos en un cúmulo de interpretaciones realizadas ya por los estudiosos de la estoa, que dejan un atisbo de esperanza de volver a un nuevo ciclo cósmico, aunque les quepa solamente a los sabios. Tal situación no le está reservada al hombre común. Recordemos que en el complejo esquema de la física estoica, los hombres mucho antes que los minerales, los vegetales y los animales, son alcanzados por la dimensión del logos -que inficiona la materia corporal-.

Este universo cerrado y material, es dinamizado por el logos, es análoga a la energía de nuestra modernidad. Otorgándole una fuerza inusitada a la materia, configurando así el cosmos, en el vértice del sistema estoico.

Para el estoicismo antiguo todo es materia corporal, el universo en su totalidad encierra los caracteres de la materialidad sostenida con principios que convocan a la memoria a una filosofía extraña para la época -que se batía en un franco ascenso hacia lo científico, prueba de ello son las divisiones en disciplinas que ya encontramos en Aristóteles: Precisamente su doctrina se inviste del pensamiento presocrático de Heráclito. Es este cosmos totalizante, que posee la característica de: continuo, llegando a tener como límite solo al vacío. El vacío, el tiempo, el espacio y lo decible (lektón) conforman el ámbito de lo incorpóreo, al no existir, son subsistentes, y por ende, poseyendo lazos de dependencia con el ámbito corpóreo.

Los estoicos desacuerdan con el principio físico de impenetrabilidad de los cuerpos, es decir, que dos cuerpos no pueden ocupar al mismo tiempo un mismo espacio, sin embargo, hacen posible la teoría de la mezcla y la fusión de unas materias y de unos cuerpos con otros. Entonces, conciben "la omnipresencia del logos como una irradiación o una permeable sustancia que cohesiona el todo y las partes materiales. En el cosmos, concebido como el organismo superior, viviente, todo se halla en contacto, y los vivientes actúan los unos sobre los otros, porque existe una simpatía cósmica y una mezcla total, de modo que todos los seres colaboran en la marcha del mundo como ser vivo." 10

El cosmos estoico posee cuatro elementos que desencadenan la existencia de la materia corporal e individual, con sus respectivas identidades. Es el elemento ígneo, que primeramente comienza a desenvolverse para pasar por los restantes elementos: aire, tierra y agua.

\footnotetext{
${ }^{10}$ Ibid., p. 136.
} 


\section{La noción de algo (“ti”).}

Resulta un tanto confusa para los estudiosos del pensamiento de la estoa, la articulación del término "ti" (el término "algo", es un pronombre indefinido). Si atendemos con cuidado al análisis del vocablo, inclusive invoca a cierta "noción supragenérica", generando con un término: -si se nos permite-, vago, tanto desconcierto. Mencionamos la palabra: desconcierto, dado que si tomamos en consideración que los estoicos se pronuncian en ámbitos conceptuales que han asentado una cosmología física con una demarcación monista clara, y para desenvolverse requiere de una exposición doctrinaria, de ciertos esquemas que contemple el dualismo: propio de un lenguaje y de una mentalidad que no podían ellos- rehuir. ${ }^{11}$

En un ambiente donde el languidecer de las concepciones enmarcadas en una ontología de cuño platónico-aristotélico o porqué no también, aristotélicoplatonizante, en la que allende al ser, se postula: el bien, lo inefable o "nada" (o sea, no hay nada). Entonces los estoicos no postulan ni lo uno ni lo otro. Por eso, es justo el calificativo de "lo indefinido". Este término: "ti" (algo) viene a significar una unicidad, que sirve de contención a la dualidad en que habían caído inmersos, al quedar constreñidos en una dualidad: corpóreos e incorpóreos, pero con la novedad tan original que defienden un monismo, cual es el del "logos". Ha habido diversas posturas relativas a si éste término: "ti" (algo) pertenece a un plano de la lógica o no.

La noción "ti" que elabora el lenguaje filosófico de la estoa, acude de modo de sostener una antítesis conformada por lo corpóreo por un lado, y por lo incorpóreo por el otro. Esta noción que contiene a ambas se yergue así en una "noción supra genérica". ${ }^{12}$ Long-Sedley, interpretan que estamos ante la presencia de un género primario. ${ }^{13}$ Esta acepción que ellos emplean, este pronombre indefinido, va basculando entre lo corpóreo y lo incorpóreo. Podemos hacer constar dos tipos. Entre lo incorpóreo, en uno de los tipos, al tiempo y al espacio, tomados como tal, operando cual si fuesen condicionantes de lo corpóreo. El tiempo y el espacio no poseen existencia, por lo tanto son subsistentes. La segunda consideración de "ti" como incorpóreo está dada por las "entidades" ficticias. Son aquellas imágenes provenientes de la actividad mental o de la imaginación de un sujeto. ${ }^{14}$

\footnotetext{
${ }^{11}$ Juliá, V. Boeri, M., "La física del estoicismo antiguo III. Cosmología y géneros del ser"en Méthexis, Revista Argentina de filosofía antigua (1990), 17.

12 Ibid., p. 17.

${ }^{13}$ Long, A.-Sedley, D. 1987, The hellenistic philosophers, 1, Cambridge University Press, New York, p. 164.

${ }^{14}$ La física del estoicismo antiguo op., cit., pp. 17-18.
} 
Según la perspectiva estoica, no hay vínculo alguno entre "el objeto del pensamiento y lo que es real" -lo existente-.${ }^{15}$. Los incorpóreos se hallan del todo subordinados a lo existente. Pues, el lektón depende de una representación de la mente, el lugar depende de los cuerpos, el tiempo depende del movimiento. ${ }^{16}$

\section{Consideraciones finales}

Con el pronombre indefinido "algo" (ti), los estoicos procuran diferenciarse de la influencia de la concepción filosófica platónica y aristotélica. Es en el lenguaje, dónde encuentran una vía de antítesis - con la que llaman, poderosamente la atención- a los dos ámbitos con que se valen para explicitar su cosmología física, de un acentuado monismo. Con el término "algo", refieren tanto a corpóreos como a incorpóreos. Lo corpóreo es el eje discursivo propio. Lo corpóreo existe, sea la naturaleza, el logos, los elementos como: el fuego, el aire, la tierra, el agua. Lo incorpóreo no posee notas de existencia, por ende, es inexistente, es decir: es subsistente. Así, el tiempo depende del movimiento, el lektón de la representación de la mente. No obstante, "algo" como incorpóreo, es un condicionante para las interacciones de los cuerpos. Este "algo" a que recurren -y de difícil aprehensión-, está alojado en el interior del lektá, y consentiríamos ya, de que estamos ante un tipo especial de lektá, que posibilita un discurso físico-cosmológico, en lo extremamente general y abstracto, siendo posible encuadrarlo también como un cuasi trascendental. ${ }^{17}$

\section{Referencias.}

García Gual, C. e Imaz, M. (1986), La filosofía belenística: éticas y sistemas, Cincel, Madrid.

Boeri, M. (2003), Incorpóreos, tiempo e individuación en el estoicismo. A propósito de "Tiempos, objetos y sucesos en la metafísica estoica" de Ricardo Salles, Dianoia, XLVIII, número 51, pp.181-193.

Boeri, M. (2001), The stoics on bodies and incorporeals, the Review of Metaphysics, pp. 723-752.

15 Ibid., pp. 18

16 Ibid., p. 18.

${ }_{17}$ Ibid., pp. 17-18. 
Bréhier, E. (1988), Historia de la Filosofía, traducción de Juan Antonio Pérez Millán y María Dolores Morán, Tecnos, Madrid.

Cicerón, (2003), Sobre los deberes, traducción de José Guillén Cabañero, Alianza, Madrid.

Disandro, C. (1959), Naturaleza de las cosas, traducción de Carlos Disandro, Andes, La Plata.

Epicteto, (2001), Manual, Disertaciones por Arriano, traducción de Paloma Ortiz García, Gredos, Madrid.

Juliá, V., Boeri, M. y Corso, L. (1998), Las exposiciones antiguas de ética estoica, Editorial Universitaria de Buenos Aires (Eudeba), Buenos Aires.

Juliá, V. y Boeri, M. (1990), "La física del estoicismo antiguo III. Cosmología y géneros del ser" en "Méthexis, Revista Argentina de Filosofía Antigua" vol. III, Fondo de Cultura Económica, Capital Federal.

Kirk, C., Raven, J. y Schofield, M. (2003), Los filósofos presocráticos, historia crítica con selección de textos, traducción de Jesús García Fernández, Gredos, Madrid.

Long, A. \& Sedley, D. (1987), The hellenistic philosophers, 1, Cambridge University Press, New York.

Marco Aurelio, (2009), Meditaciones, traducción de Bartolomé Segura Ramos, Alianza, Madrid.

Rostovtzeff, M. (1967), Historia social y económica del mundo helenístico, traducción de Francisco José Presedo Velo, Espasa-Calpe, Madrid. 